This item was submitted to Loughborough's Research Repository by the author.

Items in Figshare are protected by copyright, with all rights reserved, unless otherwise indicated.

\title{
Analysis of a novel method for low-temperature ammonia production using DEF for mobile selective catalytic reduction systems
}

PLEASE CITE THE PUBLISHED VERSION

https://doi.org/10.4271/2018-01-0333

\section{PUBLISHER}

(C) SAE International

VERSION

AM (Accepted Manuscript)

\section{PUBLISHER STATEMENT}

This work is made available according to the conditions of the Creative Commons Attribution-NonCommercialNoDerivatives 4.0 International (CC BY-NC-ND 4.0) licence. Full details of this licence are available at: https://creativecommons.org/licenses/by-nc-nd/4.0/

\section{LICENCE}

CC BY-NC-ND 4.0

\section{REPOSITORY RECORD}

Wilson, Jonathan, and Graham K. Hargrave. 2019. "Analysis of a Novel Method for Low-temperature Ammonia Production Using DEF for Mobile Selective Catalytic Reduction Systems”. figshare. https://hdl.handle.net/2134/33465. 


\section{Decomposition Analysis of a Novel Method for Low-Temperature Ammonia Production using DEF for Mobile Selective Catalytic Reduction Systems. Author, co-author (Do NOT enter this information. It will be pulled from participant tab in \\ MyTechZone)

\author{
Affiliation (Do NOT enter this information. It will be pulled from participant tab in MyTechZone)
}

\begin{abstract}
The worldwide introduction of new emission standards and new, more encompassing, legislating cycles have led to a need to increase both a selective catalytic reduction (SCR) system's capacity and conversion efficiency. To this end, it is important for an SCR system to operate to the extremes of its temperature range which in many systems is currently limited by the temperature at which diesel exhaust fluid (DEF) can easily decompose without the formation of deposits.
\end{abstract}

This paper analyses a new system for low-temperature ammonia provision to the SCR reaction. Ammonia Creation and Conversion Technology (ACCT) uses pressure controlled thermal decomposition of DEF followed by re-formation to form a fluid with greater volatility and the same ammonia density as DEF. A dosing strategy can be employed with any combination of DEF and ACCT solution to provide ammonia as a reductant over the entire temperature range of the catalyst.

High-speed shadowgraphy data identifies ammonia production below $100^{\circ} \mathrm{C}$ with rapid decomposition and full water vaporisation above $100^{\circ} \mathrm{C}$.

This study has also equipped an optically accessible hot flow, diesel exhaust simulation rig with a prototype ACCT device. The optical components allow rapid visual verification of deposit growth for bench-marking urea-based system. At a variety of exhaust temperature and mass flow conditions, the study identified a minimum deposit limited working temperature for DEF of approximately $200^{\circ} \mathrm{C}$ whereas ACCT solution was shown not to form any deposits and readily generate ammonia as low as $100{ }^{\circ} \mathrm{C}$. Further to this, gaseous species quantification using FTIR techniques has shown ammonia release in an $800 \mathrm{~mm}$ flow path for ACCT solution to be in excess of $80 \%$.

The study has demonstrated the effectiveness of ACCT at extending low temperature operating limits of DEF based SCR systems thereby increasing the total possible NOx conversion.

\section{Introduction}

Modern diesel engines are now equipped with a suite of advanced clean emission technology and have dramatically reduced their environmental burden since the introduction of increasingly tight regulations. Significant improvements have been made with the European Union reporting a reduction in most legislated emissions for the transport sector[1]. Most notably is SOx which in 2014 was only $20 \%$ of its 2000 levels (EU-28 Countries).

Despite overall emission reductions, NOx remains a prominent global health problem and with transportation contributing $46 \%$ of all NOx emissions in 2014[1], coupled with other key emissions such as particulate matter this has contributed towards a trend of diesel engine vilification. As a result the market share for diesel passenger cars has begun to gradually decline.

As Diesel engines have been shown to offer a significant $\mathrm{CO}_{2}$ saving over gasoline [2] the introduction of greater $\mathrm{CO}_{2}$ limitations beginning in 2019 [3] make it desirable to find effective solutions to decrease other emissions and prolong the life of the on-highway diesel engine.

SCR (Selective Catalytic Reduction) is an exhaust after treatment system which treats oxides of nitrogen in a reducing reaction with ammonia. One of the major hurdles involved with effective SCR systems is a reliable method for the delivery of ammonia. Due to the high toxicity and concerns over accidental release it is impractical to transport or store compressed ammonia on vehicle. The current industrially accepted method for safe ammonia storage is the use of DEF or AUS $32[4,5]$ which is injected into the hot exhaust to promote decomposition via first thermolysis then hydrolysis [6][7][8]. The process must be carefully controlled to prevent formation of deposits that could consist of crystalline urea or a number of molecules with greater thermal stability including biuret, melamine, cyanuric acid etc.[9,10]. Despite significant research into advanced mixing, decomposition, and spray characteristics it remains difficult to dose significant quantities of DEF below $200^{\circ} \mathrm{C}$. The decomposition of AUS 32 is becoming the limiting factor in the operation of SCR systems. Improving catalysts are capable of much lower operation with copper zeolite or iron zeolite catalysts currently in use shown to be operational at temperatures around $150^{\circ} \mathrm{C}$ when an appropriate $\mathrm{NO} / \mathrm{NO}_{2}$ ratio is observed [11]. Further novel manganese formulations have shown activity significantly lower and are shown to still be operational at $80^{\circ} \mathrm{C}[12,13]$.

Ammonia creation and conversion technology (ACCT) is a new system that is capable of altering the chemical composition of AUS 32 DEF. This system is installed on engine and gradually generates the new solution using only AUS 32 DEF. The new fluid comprised ammonium carbamate in solution with water which has a much simpler decomposition pathway to produce ammonia than the urea network and therefor allows the production of ammonia at significantly lower exhaust temperatures. This paper will briefly

Page 1 of 13

$10 / 19 / 2016$ 
discuss the ACCT system followed by an in depth analysis of the decomposition of the ammonium carbamate solution generated.

\section{The ACCT system}

The Ammonia Creation and Conversion Technology (ACCT) is designed to generate small quantities of ACCT solution using DEF as its only reagent. Figure 1 depicts one possible configuration for an ACCT installation.

The ACCT Reactor (Figure 1 - 6) is fed with metered (Figure 1 - 3) DEF supplied by either a dedicated or existing DEF pump (Figure 1 1,6). The reactor maintains conditions for complete thermolysis and hydrolysis $[9,14]$ of the urea to form a gaseous stream, this reaction can be simplified to Eq. (1).

$$
1 \mathrm{CO}\left(\mathrm{NH}_{2}\right)_{2}+6.92 \mathrm{H}_{2} \mathrm{O} \rightarrow 2 \mathrm{NH}_{3}+1 \mathrm{CO}_{2}+5.92 \mathrm{H}_{2} \mathrm{O}
$$

Cooling a gas stream containing ammonia and carbon dioxide will form ammonium carbamate; inclusion of the steam will allow the ionic disassociation as it dissolves in the condensed water.

$$
2 \mathrm{NH}_{3}+1 \mathrm{CO}_{2}+5.92 \mathrm{H}_{2} \mathrm{O} \rightarrow 1 \mathrm{NH}_{4}\left(\mathrm{H}_{2} \mathrm{NCO}_{2}\right)
$$

As the ammonium carbamate solution is generated continuously and at a rate proportional to the available energy it is desirable to store the solution in a small intermediate tank (Figure 1 - 7) for direct injection into an exhaust stream. Controlling ACCT dosing (Figure 1 - 5) can be achieved using either a metering valve or a metering pump as required. This reservoir of ACCT solution can then provide ammonia at any point during the cycle where either the gas temperature becomes too low for direct injection of DEF into the exhaust or the total requested ammonia quantity exceeds that possible by dosing of DEF alone.

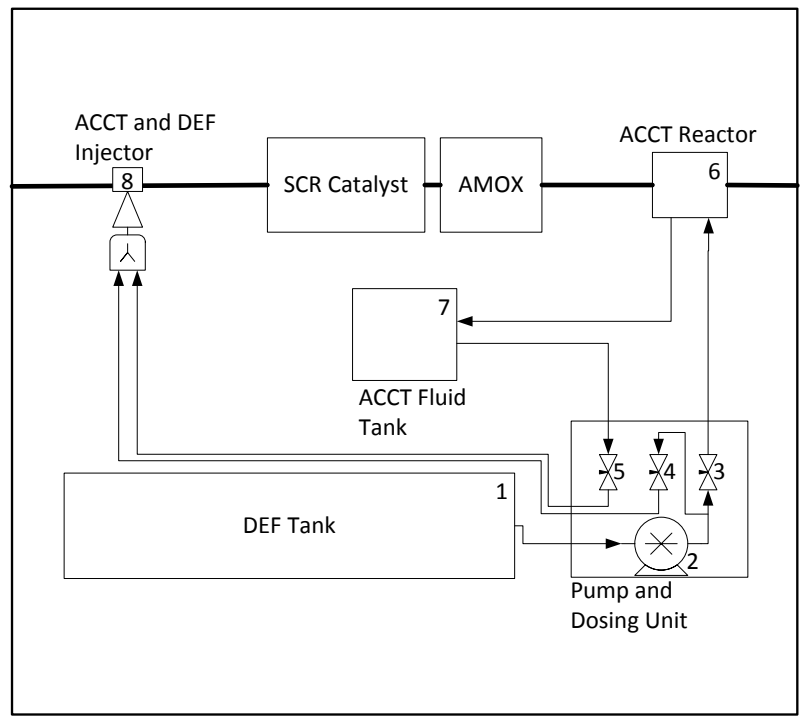

Figure 1 ACCT system architecture when installed on a typical heavyduty diesel setup with the intention of dosing both DEF and ACCT solution.

Page 2 of 13
For the large ammonia quantities required in heavy duty SCR systems, dosing of both fluids cuts down on the total ACCT systems space claim by minimising storage tank and reactor volumes. If required, especially for very low temperature cycles, a larger ACCT system can be installed as the sole provider of ammonia to the exhaust.

ACCT solution can provide ammonia reliably at temprautres of $100^{\circ} \mathrm{C}$ and above. This effectively extends the low-temperature operating capability of an SCR system to that similar to a system operating on pure ammonia gas. Literature demonstrates an increase of SCR $\mathrm{NO}_{\mathrm{X}}$ conversion at all exhaust temperatures when dosing with gaseous ammonia over AUS 32 DEF [15] and the addition of low temperature catalysts offers an attractive soloution for a large increase in total $\mathrm{NO}_{\mathrm{X}}$ converison.

\section{Decomposition of fluid}

Enthalpy of formation data from Koebel and Strutz[16] publication on urea decomposition is depicted in Table 1.

Table 1 Enthalpy of formation figures for DEF constituents and products at standard conditions 298.15k and 1bar [16]

\begin{tabular}{|l|c|c|}
\hline \multicolumn{1}{|c|}{ Compound } & mol wt & $\begin{array}{c}\Delta \mathrm{H}_{\mathrm{f}} \\
(\mathrm{kJ} / \mathrm{mol})\end{array}$ \\
\hline urea(s) & 60.058 & -333.101 \\
\hline ammonia(g) & 17.03 & -45.904 \\
\hline carbon dioxide(g) & 44.01 & -393.498 \\
\hline water(l) & 18.016 & -285.829 \\
\hline water(g) & 18.016 & -241.814 \\
\hline
\end{tabular}

One kilogram of AUS 32 is equivalent to 5.411 mols urea and 37.47 mols water which, results in a total enthalpy of formation of 1802.4 $\mathrm{kJ}$ and $10712.4 \mathrm{~kJ}$ respectively.

In order to compensate for the endothermic process of dissolving urea Koebel and Strutz [16] have defined an equation to approximate the integral heat of solution $\left(\Delta \mathrm{H}_{\mathrm{L}}\right)$ which is $13.54 \mathrm{~kJ} / \mathrm{mol}$ urea.

This results in a total $\Delta \mathrm{H}_{\mathrm{f}(\mathrm{AUS} 32)}=-12441.5 \mathrm{~kJ} / \mathrm{kg}$

Using the same data for the decomposed product with $1 \mathrm{~kg}$ AUS32 yielding $5.418 \mathrm{~mol} \mathrm{CO}_{2}, 10.837 \mathrm{~mol} \mathrm{NH}_{3}$ and $32.076 \mathrm{~mol} \mathrm{H}_{2} \mathrm{O}$ with enthalpies of formation of $-2132.0 \mathrm{~kJ},-497.5 \mathrm{~kJ}$ and $-7756.4 \mathrm{~kJ}$ respectively.

This results in a total $\Delta \mathrm{H}_{\mathrm{f}(\text { products })}=-10565.9 \mathrm{~kJ} / \mathrm{kg}$

Therefore the required energy input for decomposition is:

DEF AUS $32 \Delta \mathrm{H}_{\text {decomposition }}=1875.6 \mathrm{~kJ} / \mathrm{kg}$

Utilising the Extended UNIQUAC model [17-19] to predict the ionic equilibrium of the solution at $25^{\circ} \mathrm{C}$, ACCT solution has been calculated to have a enthalpy of formation of $\Delta \mathrm{H}_{\mathrm{f}(\mathrm{ACCT})}=-12641.8 \mathrm{~kJ} / \mathrm{kg}$ 
As the products of the ammonium carbamate solution are identical to the products for decomposed DEF the required energy for decomposition is calculated to be $\Delta H_{\text {decomposition }}=2075.91 \mathrm{~kJ} / \mathrm{kg}$

Despite an overall increase in energy to decompose ACCT solution, a dramatically lower decomposition temperature threshold changes the way a decomposing droplet behaves. In order to gain an understanding of this behavior, a simplified single drop on a hot surface experiment has been conducted to compare ACCT solution to both water and DEF. Using high speed shadowgraphy provides highly detailed visual comparison of the droplet breakup. This has then been carried over to an exhaust simulation rig to demonstrate the decomposition of ACCT solution in a simulated exhaust flow with full optical access and chemical monitoring of the evolved species.

\section{Experimental setup}

Generation of a single droplet is achieved using a syringe pump to provide a continuous micro-dose of fluid to a $30 \mathrm{G}$ hypodermic needle suspended vertically with a $60^{\circ}$ point $0.3 \mathrm{~mm}$ outer diameter and $0.16 \mathrm{~mm}$ inner diameter. This method allows a droplet to be generated which detaches from the needle at a repeatable point where the total mass overcomes the droplets adhesion. This droplet diameter is repeatable for a single fluid type however results in very minor changes in droplet diameter relative to the surface tension properties of each specific fluid.

A 316 polished stainless steel surface has been chosen for impaction, this is an arbitrary selection designed to mimic typical materials used for walls and mixers in SCR application whilst providing a surface that will not be affected by the experiment to provide a consistent surface roughness for accurate comparison between the different fluids. A surface $\mathrm{K}$ type thermocouple was selected as an exposed junction thermocouple allows for the closest coupling to the surface temperature and the high chemical resistance of type $\mathrm{K}$ thermocouples allows this to operate in the presence of ammonia. The thermocouple has a rather low accuracy of $\pm 2.2^{\circ} \mathrm{C}$ however has a much higher repeatability hence the same thermocouple has been used for all comparable tests. To ensure a single surface temperature measurement would provide an accurate enough representation of the surface temperature at the point of impaction a second stainless steel plate was produced and surface coated with high temperature matt black paint to provide an emissivity of 1 . Use of an E-60 thermal camera, produced by FLIR, then confirmed a temperature deviation over the region of interest of less than $1^{\circ} \mathrm{C}$ at all test conditions.

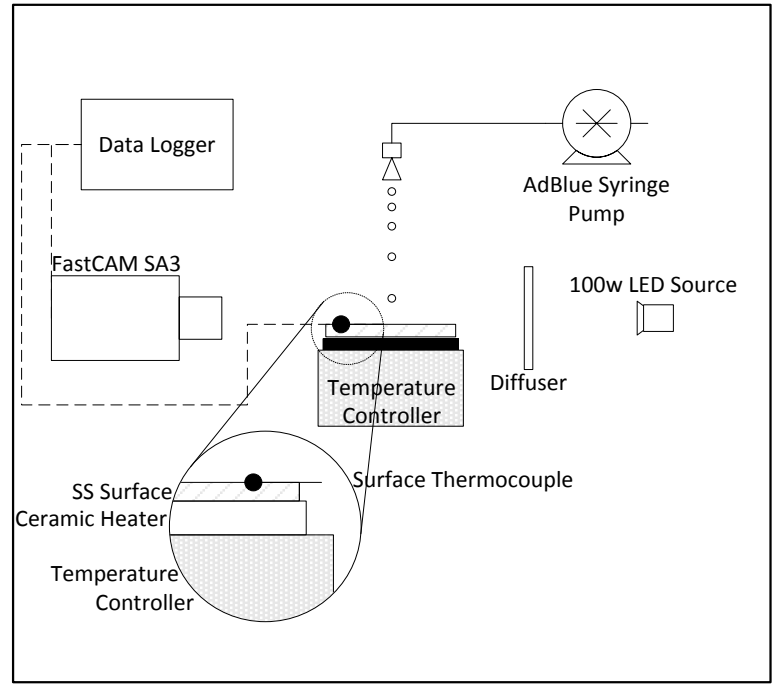

Figure 2 High speed Shadowgraphy setup of droplet impaction on a hot surface

Droplet impaction has been captured using a Photron FastCAM SA3 high speed camera set to capture a region of $1024 * 496$ pixels at 4000 fps with a $1 / 50000 \mathrm{~s}$ exposure to eliminate motion blur. A high intensity $100 \mathrm{~W}$ LED backlight is used couples with a diffuser to give continuous even illumination, shuttering is handled by the camera.

A Sigma $200 \mathrm{~mm}$ lens set to f8 results in a DOF of approximately 0.2 $\mathrm{mm}$ which is sufficient to represent a 2D plane aligned with the vertical axis of the falling droplet.

Internal RAM limitations of the camera allowed for a capture of 600 ms video which was sufficient to capture approximately $400-500 \mathrm{~ms}$ of data from point of impaction when relying on manual triggering alone. Where this is sufficient to look at the impaction and initial decomposition to provide further data on the droplet decomposition a second set of data is taken at full frame of $1042 * 1024$ pixels and 500 fps allowing a $2.72 \mathrm{~s}$ total recording time.

\section{Image processing}

Images of a graticule have been taken at intervals throughout data collection; this has been used to calibrate the pixel size for each of the images. Using the image processing software suite Image [20], droplet diameter and velocity are calculated as well as any further necessary measurements of the droplet breakup.

Following collection of videos for 2 frame rates, 3 fluids at 5 temperature set points with several repeats it becomes impractical and inaccurate for a visual comparison of the data. To provide comparable information between the whole data set a Matlab script has been used to batch process the data. First preforming an edge finding technique, the process highlights each individual droplet ejected from the decomposing/boiling fluid. A Canny filter has been used over the basic Sobel as it is much more likely to produce a single, continuous closed boundary around each droplet due to its use of a Gaussian convolution smoothing filter and identification and inclusion of weak edges that are connected to strong edges to create closed shapes. Controlling the threshold values allows for only droplets that are contained within the $0.2 \mathrm{~mm}$ DOF to be detected, the 
$0.018 \mathrm{~mm}$ per pixel spatial resolution of the camera also limits detection to droplets above $100 \mu \mathrm{m}$. Following edge detection a binary image boundary detection algorithm can then be used to catalog each droplet and its area.

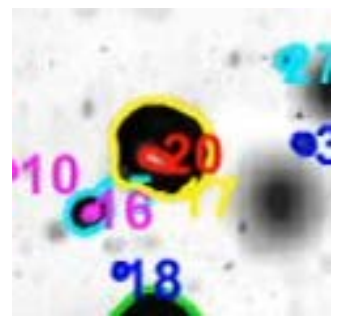

Figure 3 Example of parent and child features creating a false droplet count.

The Canny filter has provided continuous edge , however, has also created an edge internally inside many droplets due to the lensing effect of the sphere. This creates a false droplet and is dealt with by programmatically removing all child boundaries that have been identified within another parent boundary.

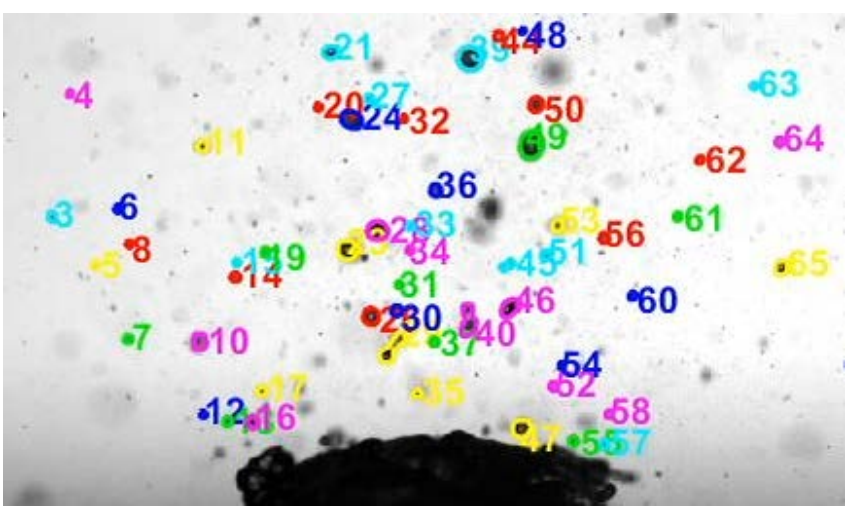

Figure 4 Ejected droplet quantification

Quantification of ejected droplets gives an indication of breakup and boiling effects after surface impaction.

\section{Results}

Spatial measurements confirm that the mean droplet diameter is 2.3 $\mathrm{mm}$ with a deviation of $\pm 0.1 \mathrm{~mm}$ which equates to a volume of $0.00637 \mathrm{ml}$ with a maximum deviation of $\pm 0.00083 \mathrm{ml}$. The variation is mainly between fluids due minor changes in surface tension and density, however, as a small diameter change represents a notable change in volume it must be considered when comparing fluids. The smallest droplets have been produced by water in a size range of 2.2 $-2.3 \mathrm{~mm}$ followed by AUS 32 with a size of $2.25-2.35 \mathrm{~mm}$ and finally ACCT solution with the largest droplet diameters of $2.3-2.4$ $\mathrm{mm}$.

Velocity was found to be much more consistent with droplet velocities measured across 11 frames with frame spacing of $0.25 \mathrm{~ms}$ in which time the droplet traveled approximately $4.15 \mathrm{~mm}$. This equates to droplets having a consistent velocity of $1.505 \mathrm{~m} / \mathrm{s}$ at point of impaction, this is an average velocity over the time the droplet is in frame. If the distance measured over is $4.14 \mathrm{~m} / \mathrm{s}$ and negating and air resistance the droplet should have accelerated by $0.081 \mathrm{~m} / \mathrm{s}$ over this period and hence the actual velocity is $0.0407 \mathrm{~m} / \mathrm{s}$ higher than that calculated making it $1.546 \mathrm{~m} / \mathrm{s}$.

\section{Water}

Data for water droplet impaction provided predictable results in line with that already shown in literature[21,22]. It can be seen in Figure 5 that at $117.3^{\circ} \mathrm{C}$ nucleate boiling is observed after approximately $130 \mathrm{~ms}$ although the process is slow, the rate of boiling increases as the bulk temperature of the fluid moves towards the boiling point. Rapid transition boiling occurs at $163.2^{\circ} \mathrm{C}$ within 4 ms after impaction and demonstrates the greatest evaporated mass within the allotted $250 \mathrm{~ms}$. Beyond this temperature the Leidenfrost effect becomes dominant with $208{ }^{\circ} \mathrm{C}$ representing a transitional point where droplet momentum can still temporarily overcome the effect and locally cool the surface to enable transitional boiling to occur. The surface temperature quickly recovers shifting the governing effect to much slower film boiling.

These effects are well understood and provide a water baseline for comparison to ACCT solution and DEF, Figure 6 shows a summary of the different heat transfer regimes and their effect on the total evaporation time for the droplet as depicted by Liang and Mudawar[21].

\section{Page 4 of 13}




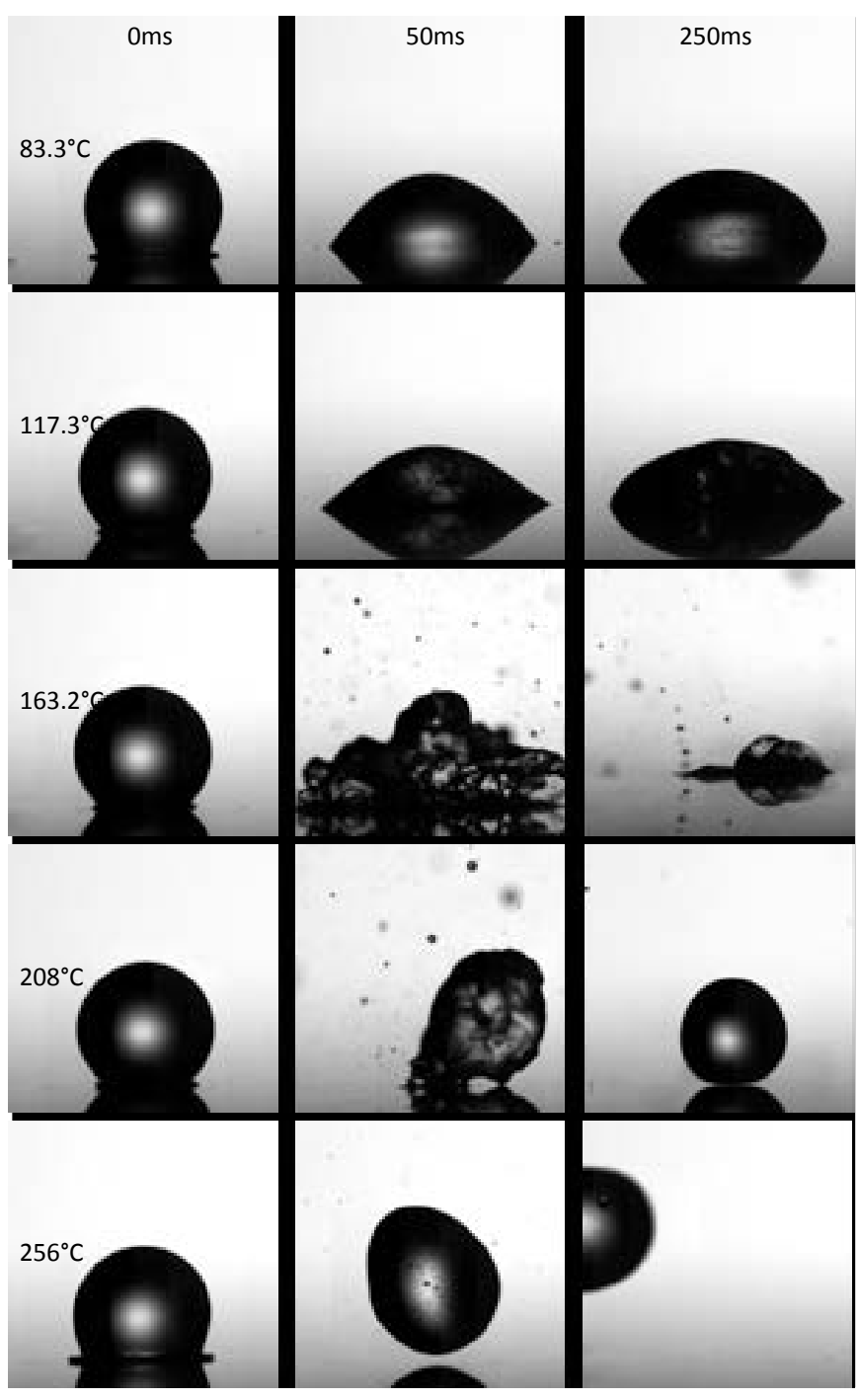

Figure 5 High speed Shadowgraphy of a water droplet on a surface heated between 83.3 and $256^{\circ} \mathrm{C}$ at 0,50 and $250 \mathrm{~ms}$ after intital impaction.

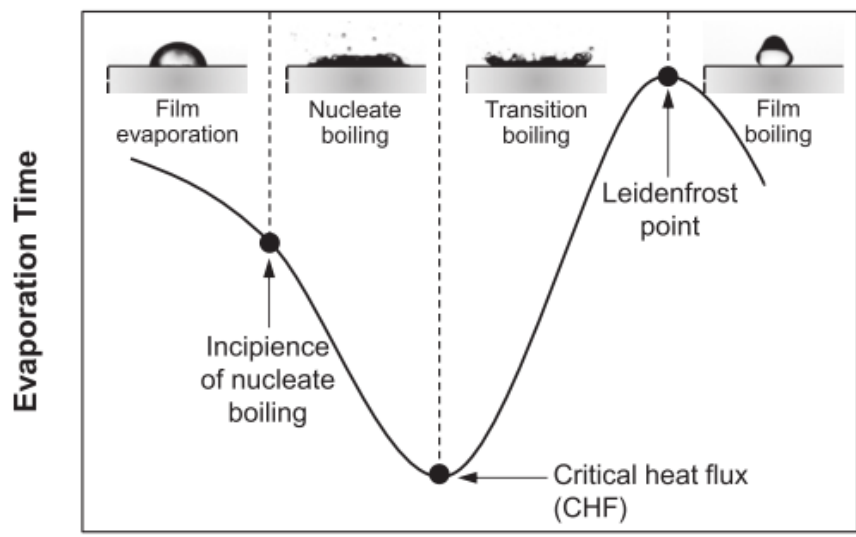

Wall Temperature

Figure 6 Heat transfer regimes for droplet impaction on a hot surface [21]

Page 5 of 13

$10 / 19 / 2016$
Attributing the impact to one of the five impact patterns defined throughout literature [23], again water behaves predictably transitioning from wet impact at $83.3^{\circ} \mathrm{C}$ to wet boiling at $163.2^{\circ} \mathrm{C}$ to transition impact at $208{ }^{\circ} \mathrm{C}$ and $256^{\circ} \mathrm{C}$ at which by the second bounce the Weber number has decreased to the point where a dry rebound occurs.. It is noted that the Weber number for this impact was insufficient to produce a significant splashing effect so does not enter a satellite dry rebound regime and any droplet ejections occur as a result of transitional boiling or transitional impact.

\section{DEF AUS 32}

AUS 32 impaction produces very similar results to water in the first $250 \mathrm{~ms}$ after impaction. Once again the start of nucleate boiling is $118{ }^{\circ} \mathrm{C}$, followed by transition boiling at $166^{\circ} \mathrm{C}$. At this temperature some difference begins to appear, during the $166^{\circ} \mathrm{C}$ boiling the total mass reduction of the fluid is decreased compared to the corresponding droplet of water. It is likely that two effects are contributing to this, firstly a cooling effect from initial thermolysis of the urea and subsequent evaporation of the resulting ammonia and isocyanic acid. Secondly, an increase in the mass fraction of dissolved/molten urea as water vapor is lost from the droplet has the effect of increasing the boiling temperature and is likely to reach a point where the majority is molten or slowly boiling/decomposing urea which would slow the overall boiling process.

The Leidenfrost temperature has also been increased over water, this is likely as a result of an increased boiling point $\left(\sim 103^{\circ} \mathrm{C}\right)$ [24] for AUS 32. Due to the change to a transition boiling regime, $209^{\circ} \mathrm{C}$ now represents a faster mass reduction, although it is unlikely to be closer to the critical heat flux (Figure 6) than $116^{\circ} \mathrm{C}$ it is probable that the rate of urea thermolysis has dramatically increased. 


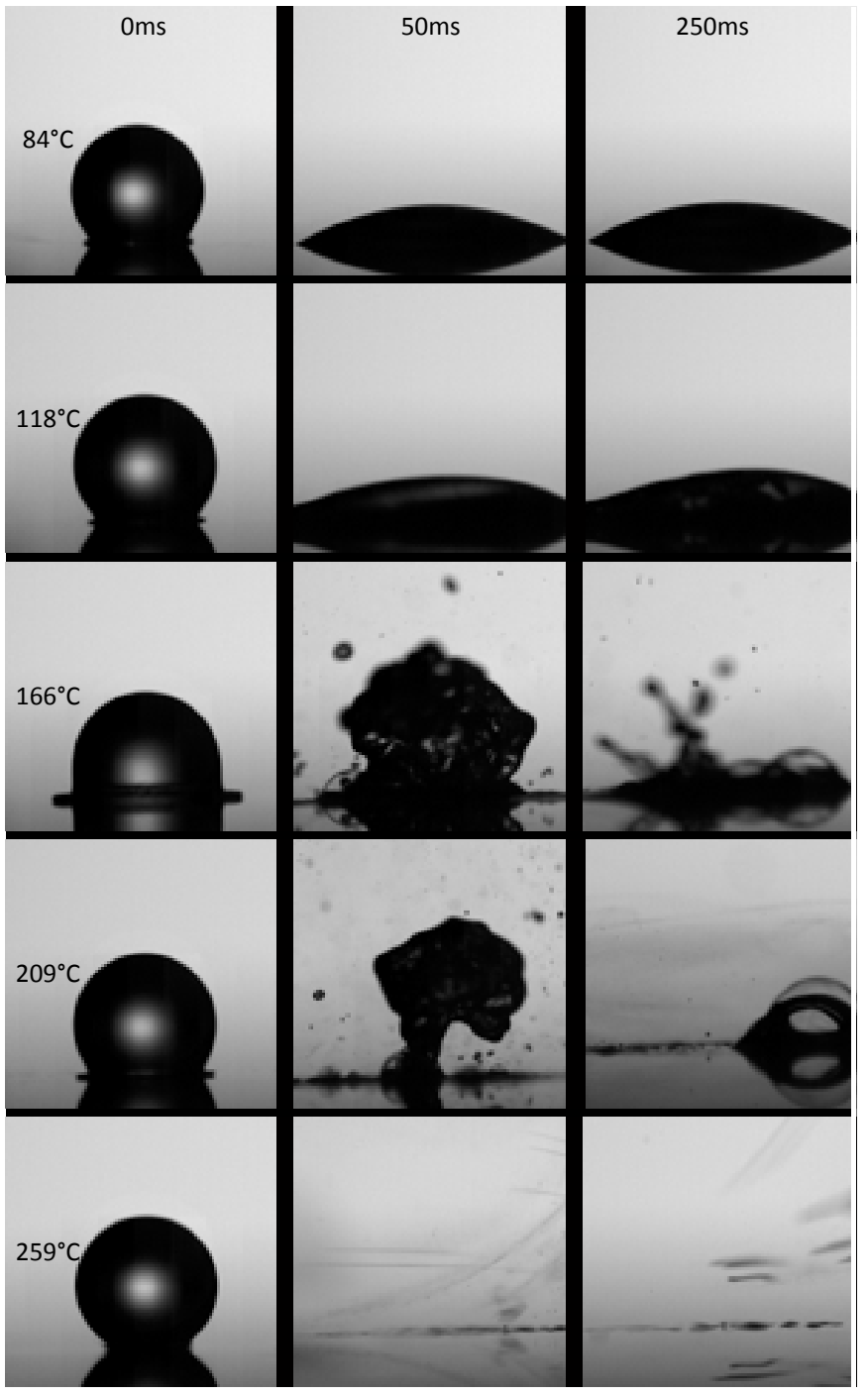

Figure 7 High speed Shadowgraphy of an AUS 32 droplet on a surface heated between 84 and $259{ }^{\circ} \mathrm{C}$ at 0,50 and $250 \mathrm{~ms}$ after initial impaction.

\section{ACCT solution}

ACCT solution represents a change in methodology over either water or AUS 32, whereas the predominant effect in the first $250 \mathrm{~ms}$ for water and AUS 32 is the boiling of water, ACCT solution is governed by the thermolysis and subsequent generation of ammonia. This theory is supported as ACCT solution has a decomposition temperature significantly lower than the boiling point of water as well as a greater enthalpy of decomposition which contributes to bulk cooling of the droplet.

Figure 8 demonstrates generation of a gas phase, either from decomposition or boiling, at the lowest recorded temperature of 84.5 ${ }^{\circ} \mathrm{C}$. As this gas is generated at the contact boundary with the stainless steel plate the gas has been contained within the droplet and begun to foam. This effect is seen to a much greater degree at $118{ }^{\circ} \mathrm{C}$ with an increased rate of gas generation, larger foam and mass ejection as individual cells within the foam collapse.

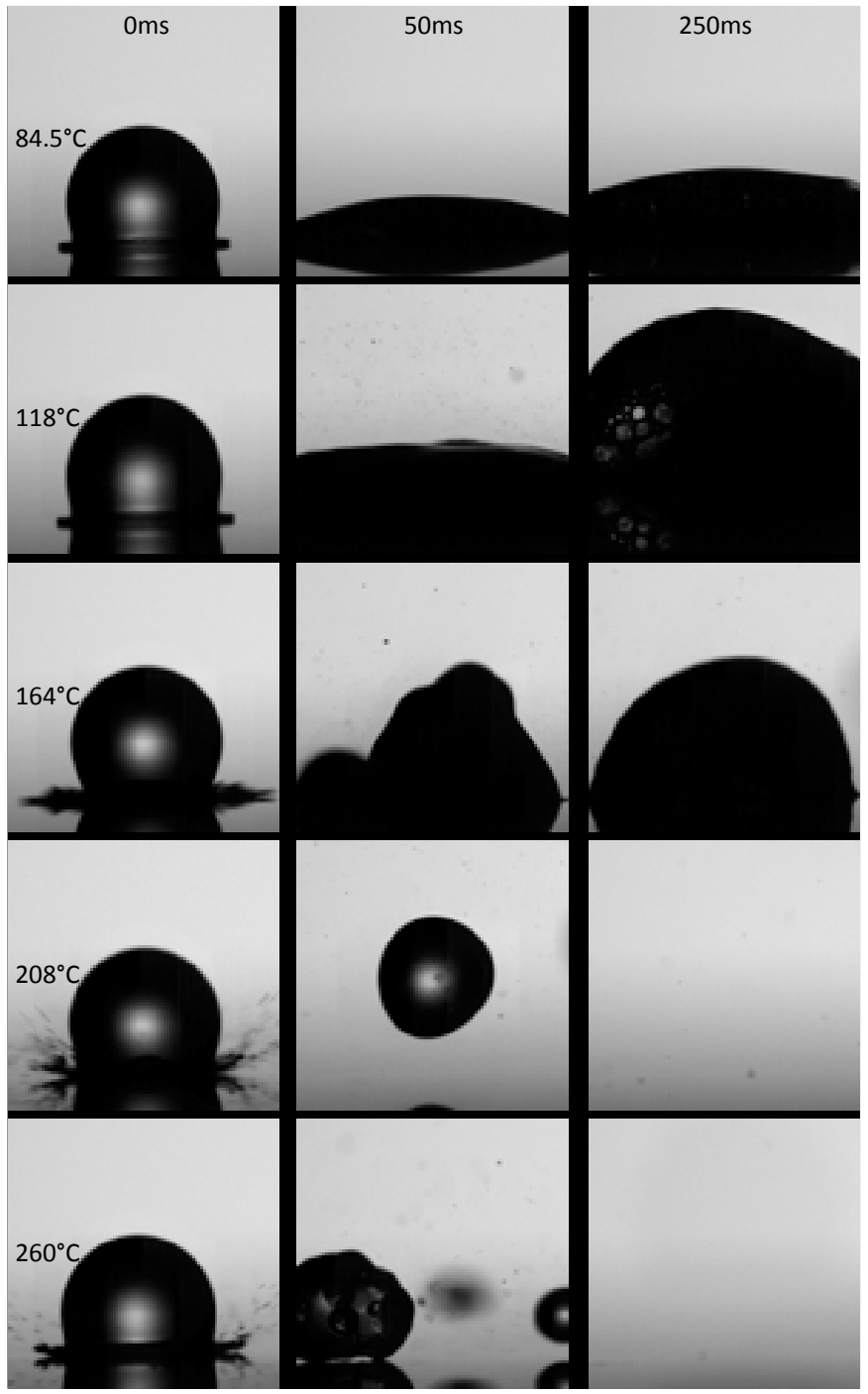

Figure 8 High speed Shadowgraphy of an ACCT solution droplet on a surface heated between 84.5 and $260{ }^{\circ} \mathrm{C}$ at 0,50 and $250 \mathrm{~ms}$ after initial impaction.

Interestingly the impaction pattern has dramatically changed and transitions from wet boiling at 84.5 and $118{ }^{\circ} \mathrm{C}$ straight to satellite dry rebound at $164{ }^{\circ} \mathrm{C}$ shown in Figure 9. Despite this for $164{ }^{\circ} \mathrm{C}$ and $209^{\circ} \mathrm{C}$ some impactions and secondary impactions have properties of a transitional impaction with a short period of mass ejection as a result of rapid boiling.

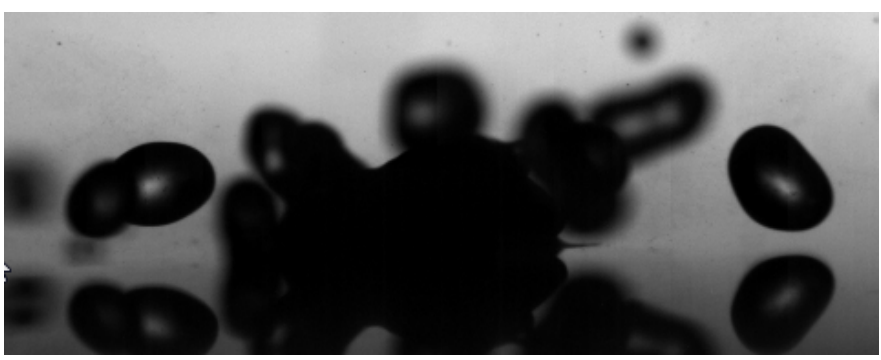

Figure 9 Satellite dry rebound of ACCT solution on a $164{ }^{\circ} \mathrm{C}$ surface 10 ms after impaction 


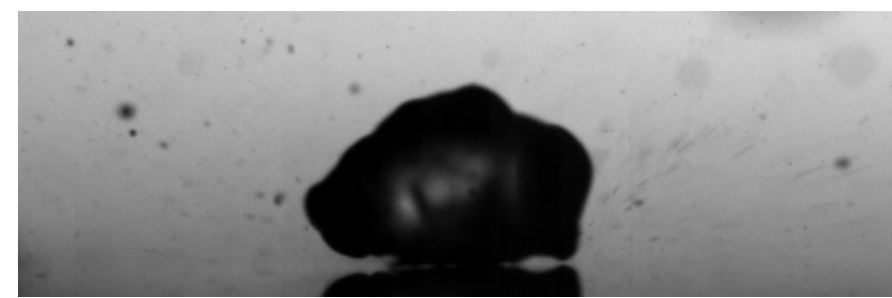

Figure 10 Transitional boiling like event for a satellite droplet of ACCT solution on a $208^{\circ} \mathrm{C}$ surface.

Although the initial effect is that of a dry rebound at $164{ }^{\circ} \mathrm{C}$ this is quickly overcome to form an attached foam. Likely this is due to the increased cooling effect of thermolysis and the resultant dip in temperature is enough to effect a regime change. It is also noted that for a small central area the droplet momentum has overcome the Leidenfrost effect and impinged on the steel surface, this has provided a nucleation site for local cooling of the surface.

\section{Ejected droplet quantification}

Using the image processing technique described above the different fluids impinging on varying temperature surfaces has been quantified. The droplet count allows identification of peaks which attribute themselves to thermodynamic regimes such as transitional boiling or transitional impaction.

As a measure of quantification, ejected droplet count supports the conclusions drawn from the original images, Figure 12. Water generated a larger number of droplets for higher temperature transitional impaction ( 208 and $256^{\circ} \mathrm{C}$ ) from the droplets initial impaction; following this a second bound results in a dry rebound as the velocity, and therefore the Weber number, is no longer great enough to overcome the Leidenfrost effect.

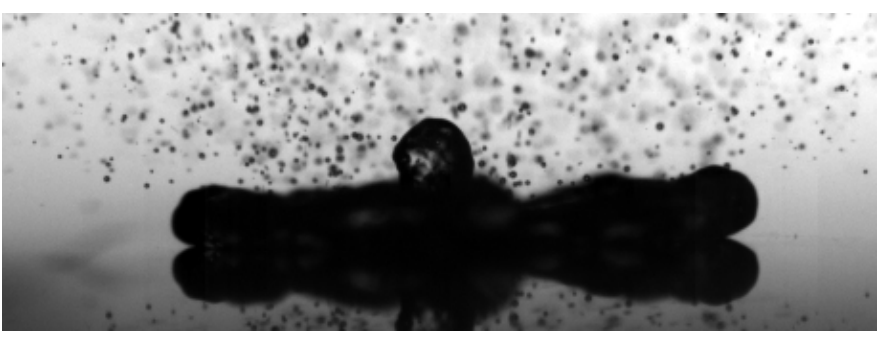

Figure 11 Transitional impaction of a water droplet onto a surface at $256^{\circ} \mathrm{C}-3 \mathrm{~ms}$ after impaction

At $163.2^{\circ} \mathrm{C}$, the temperature closest to critical heat flux, it is noted that no mass ejection occurs as a result of transitional impaction however a continuous high level of droplets are produced as a result of rapid boiling. These results closely follow the expected effects shown in literature (Figure $6[21,23]$ ).
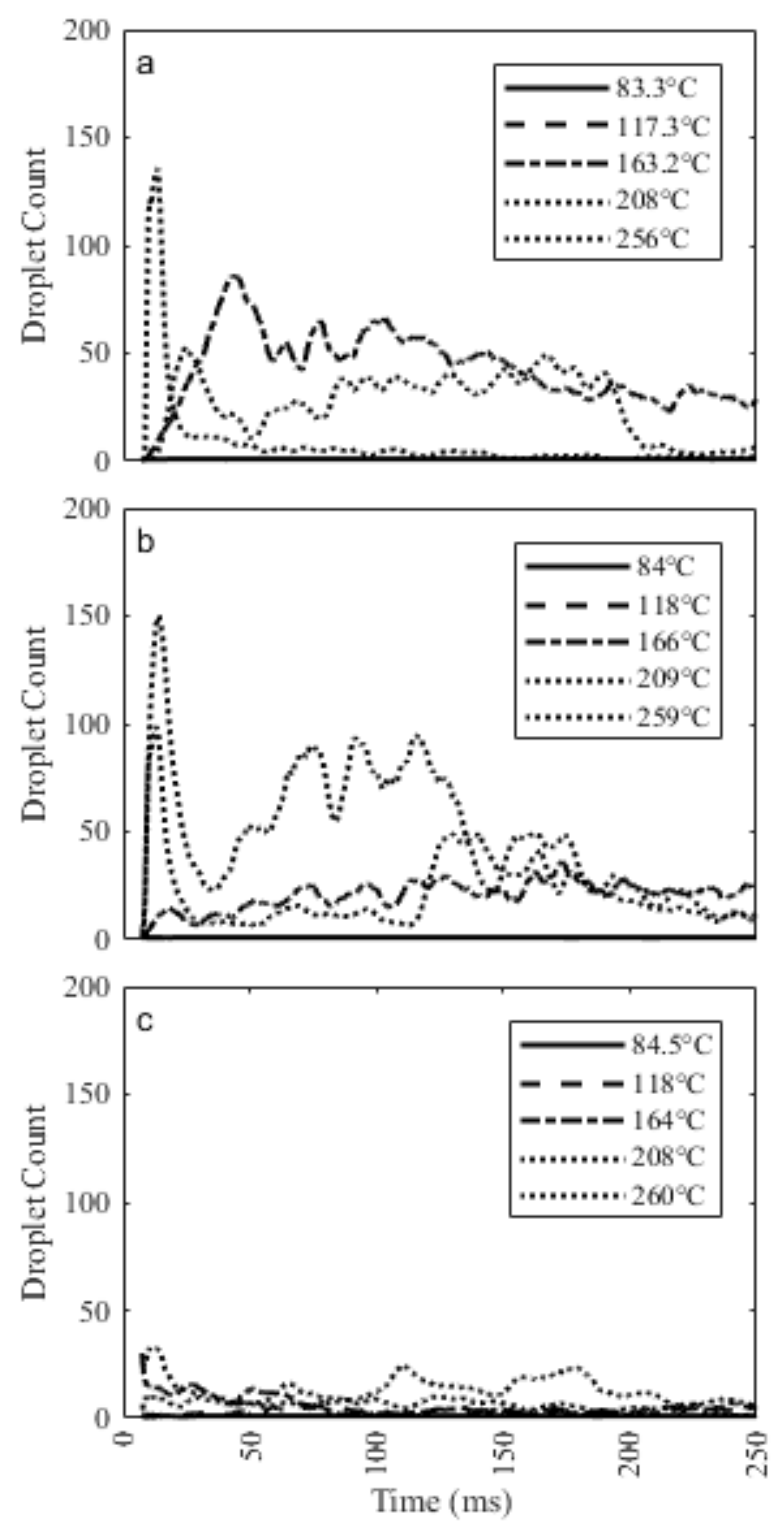

Figure 12 Ejected droplet count for a) water, b)AUS 32, c)ACCT solution at 0-250 ms from point of impaction onto various surface temperatures.

AUS 32 is shown to exhibit this same rapid boiling, however, it now occurs during the $209^{\circ} \mathrm{C}$ experiment which also exhibits a transitional impact mass ejection which suggests the initial event is sufficient to locally cool the surface to the point below the Leidenfrost where rapid boiling can occur. A droplet at this temperature that has a lower Weber number is likely to exhibit dry rebound and not become attached to the surface. $166^{\circ} \mathrm{C}$ shows rapid boiling but to a much lesser extent than the equivalent temperature with water due to both an increased energy requirement and an increased boiling point.

The results for ACCT solution are dramatically different; this is due to the primary effect no longer being the boiling of water and instead becoming decomposition and ammonia production. The solution never undergoes a transitional impaction and instead transitions directly from wet boiling to satellite dry impaction. The greatest mass ejections are, however, seen at $208{ }^{\circ} \mathrm{C}$ and are a direct result of transition like impactions of each of the satellite droplets. No rapid boiling mass ejection is seen either, because the primary method is 
decomposition and not boiling of water, the droplet tends to foam rather than boil. This results in particles being counted only once parts of the foams cellular structure collapse.

\section{Impact of droplet size}

The $2 \mathrm{~mm}$ droplet used for the experimental work above is atypical of a urea SCR spray with an example SMD 20 - $90 \mu \mathrm{m}$ [25]. Where mass and momentum are sufficient for the droplet to impact on a surface and form a film the experimental results above are directly relevant and would demonstrate the rate of boiling at different conditions. In this scenario the surface temperature will be cooled by the liquid and will stabilise at significantly lower temperatures than the flow itself. The volatility of the fluid, even at low surface temperature, would indicate that injection onto a surface at low exhaust temperatures is a valid method for SCR ammonia release. The formation of this film can be seen highlighted in Figure 17 where ACCT fluid is boiling rapidly on the mixer.

The data collected and literature [26] suggest that the decomposition of ammonium carbamate is a rapid process above $100{ }^{\circ} \mathrm{C}$. Using this assumption the time for a droplet to decompose can be equated to the time taken for the required heat transfer to occur between flow and droplet. Figure 13 estimates the time taken for a droplet to decompose in the flow alone using an assumed value for heat transfer of $10 \mathrm{~W} / \mathrm{m}^{2} \mathrm{~K}$ and a peak droplet temperature of $100{ }^{\circ} \mathrm{C}$ for full decomposition and complete the boiling of any liquid.

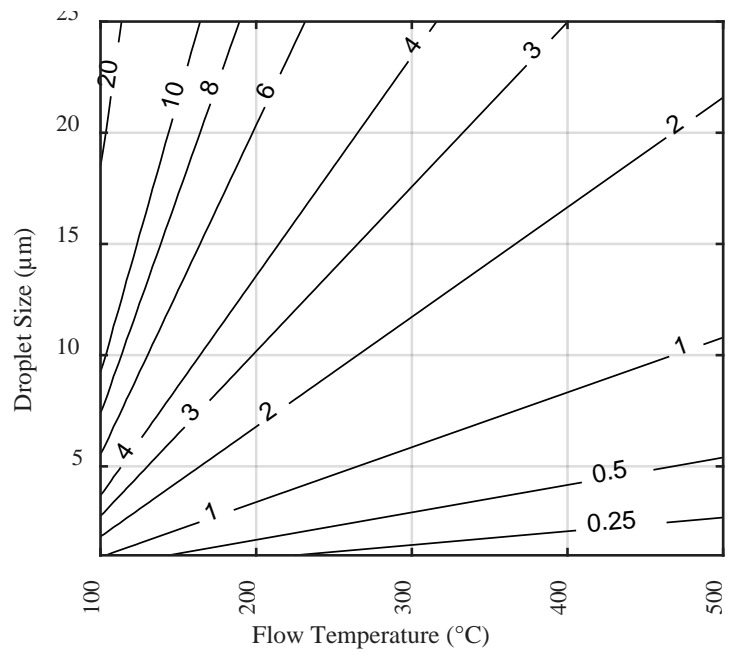

Figure 13 Time (s) taken for the required energy for decomposition to be transferred to a droplet of varying size at vary exhaust flow conditions based on an assumed forced convective heat transfer of $10 \mathrm{~W} / \mathrm{m}^{2} \mathrm{~K}$.

For the experimental work below a test section of $100 \mathrm{~mm}^{2}$, mass flow of $250 \mathrm{~kg} / \mathrm{h}$ and an injector to SCR distance of $800 \mathrm{~mm}$ results in the velocity profile shown in Table 2 .

Table 2 Flow velocities and residence time foe the test section depicted in Figure 15

\begin{tabular}{|c|l|l|}
\hline \multicolumn{1}{|c|}{$\begin{array}{c}\text { Temperature } \\
\left({ }^{\circ} \mathrm{C}\right)\end{array}$} & \multicolumn{1}{|c|}{$\begin{array}{c}\text { Flow Velocity } \\
(\mathrm{m} / \mathrm{s})\end{array}$} & \multicolumn{1}{c|}{$\begin{array}{c}\text { Decomposition time } \\
(\mathrm{s})\end{array}$} \\
\hline 100 & 7.0 & 0.114 \\
\hline 150 & 7.9 & 0.101 \\
\hline
\end{tabular}

Page 8 of 13

\begin{tabular}{|l|l|l|}
\hline 200 & 8.9 & 0.090 \\
\hline 300 & 10.7 & 0.074 \\
\hline 400 & 12.6 & 0.063 \\
\hline
\end{tabular}

Figure 13 suggests that only the very smallest droplets below $0.5 \mu \mathrm{m}$ droplets are capable of fully decomposing before reaching the SCR catalyst. This is an estimate that does not take account of effects such as bulk flow cooling from adjacent droplets however give a good indication that some form of flow mixing is required. Above this either an impaction mixer or a flow mixer can be used to increase the residence time for a droplet.

To consider the rest of the droplets, that are greater than the maximum size required for air only decomposition and do not become part of a film, we need to assess the comparability of the imaged droplet to spray droplets. A review paper on this topic by Visser et al [27] suggests that in a dimensionless comparison large scale droplet impaction data does indeed have merit for assessing smaller scale droplets.

A decrease in droplet size also decreases its mass/surface area ratio and its Weber number. This results in a droplet with a much lower kinetic energy and hence the effect of the Leidenfrost increases as the initial impact energy will not overcome the effect. Events such as that depicted in Figure 11 will therefore be less common as well as an increases propensity for a droplet to bounce. The decreased Weber number will also affect the regime, the model produced by Bai and Gosman[28] shown in Figure 14 demonstrates that with a decreased Weber number the droplet is more likely to stick, boil or rebound rather than splash and break-up.

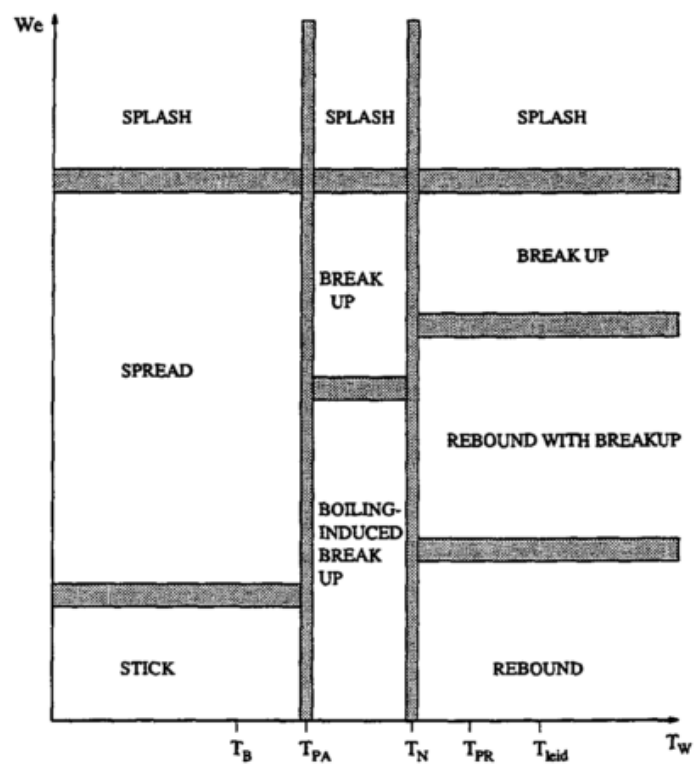

Figure 14 Overview of droplet impingement regimes and transition conditions for a dry wall at fixed Laplace number and surface roughness [28] 


\section{Diesel exhaust hot flow testing}

To assess ACCT solution for SCR use, an investigation has been carried out using an SCR system and ACCT reactor installed on a hot air flow which simulates diesel engine exhaust flow without the need for costly engine test work. This has allowed direct analysis of the inflow decomposition of the fluid using the optically accessible mixer section as well as chemical quantification of the ammonia production.

\section{Experimental setup}

\section{Rig overview}

The hot flow exhaust simulation rig used is capable of simulating a heavy duty diesel engine up to $7.2 \mathrm{~L}$, providing up to $900 \mathrm{~kg} / \mathrm{h}$ of air flow which can be electrically heated up to $600^{\circ} \mathrm{C}$ this allows the installation of optical mixer and injection sections to assess the quality of decomposition of an SCR spray with a variety of optical and chemical techniques.

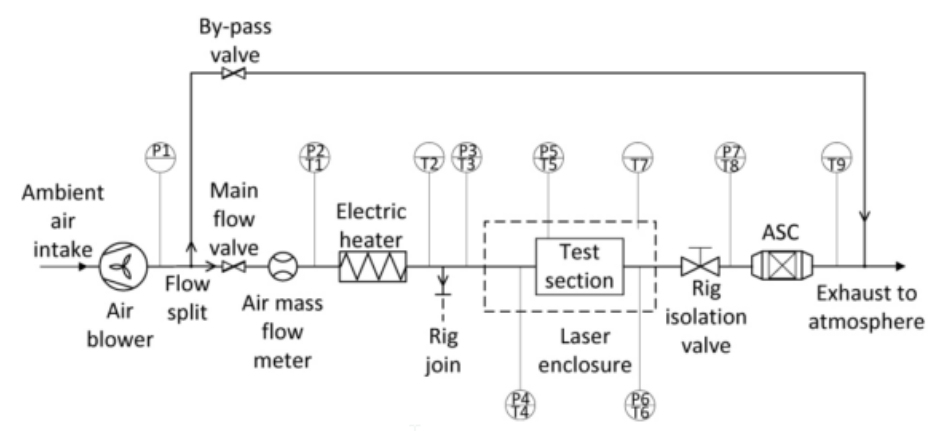

Figure 15 Schematic of the hot flow facility for diesel engine exhaust simulation.[25][29]

\section{Test section}

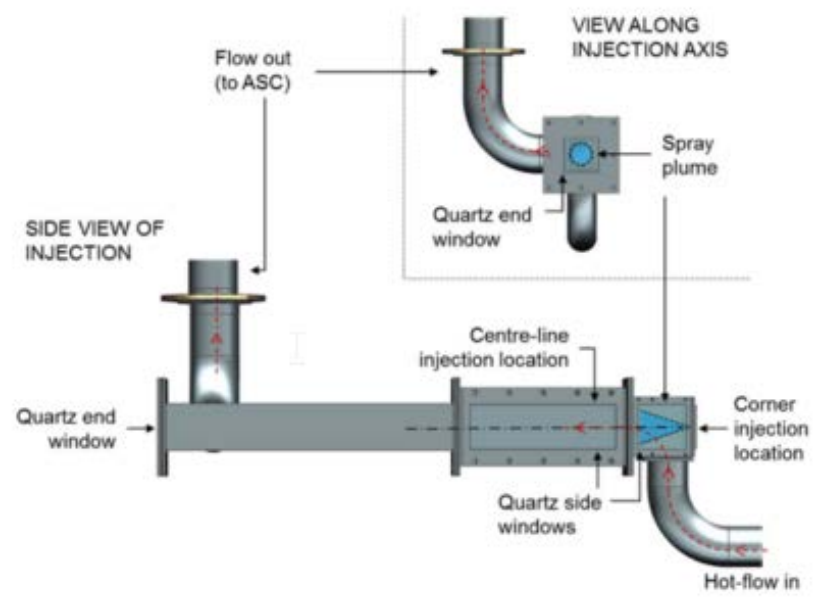

Figure 16 Idealised square test section with optical access for SCR injection.[25]

The optical test sections used has AUS 32 or ACCT injection on a $90^{\circ}$ bend with an idealized square geometry for ease of optical access. Quartz windows provide both side and views of the spray and the idealized mixer geometry employed.

Page 9 of 13
The mixer employed is a basic 3 plate mixer which is non-optimised for the flow or the injection rate. It is designed to give some mixing and some impaction surfaces for fluid injection whilst exacerbating deposit formation problems. This allows rapid comparison between AUS 32 and ACCT solution to assess deposit limitation on dosing.

Positioned $800 \mathrm{~mm}$ downstream of the injector is a duct scanning sampling probe for FTIR analysis which allows an average value to be found for ammonia concentration across the flow and eliminate error as a result of poor mixing. Chemical analysis is performed by a ThermoFisher Antaris IGS FTIR with a 2 meter gas sampling cell, heated sampling lines and an interference compensated quantifying calibration for ammonia, isocyanic acid, $\mathrm{NO}, \mathrm{NO}_{2}$ and Methane. Set for 2 scans per result each sample is attained in $1.75 \mathrm{~s}$.

The flow is comprised only of heated air and therefore has a different chemical composition to true diesel exhaust. This has both advantages and disadvantages. The lack of hydrocarbons, soot and excess water allows a much greater confidence in the FTIR results with no danger of depositing on windows and affecting quantification. When it comes to the decomposition of ACCT solution the different composition is likely to have no effect beyond a slightly different heat capacity of the flow as the decomposition relies solely on thermolysis. With urea sprays however there is the requirement for a hydrolysis step, ample water is provided for the reaction by the injection of AUS $32 \mathrm{DEF}$ with the reaction using only $14 \%$ of the available water. Because of this it is likely that only a small effect is seen on the DEF decomposition and supporting literature $[30,31]$ showing deposits on engine would suggest that any problem seen of the air flow rig are also being experienced on real world engine SCR systems.

\section{Results}

Back to back testing shows a continual buildup of urea based deposits occurring after very short times, significant deposits are shown after 30 minutes at the relatively high exhaust condition of $300{ }^{\circ} \mathrm{C}$. Figure 17 demonstrates ACCT dosing back to back with DEF.

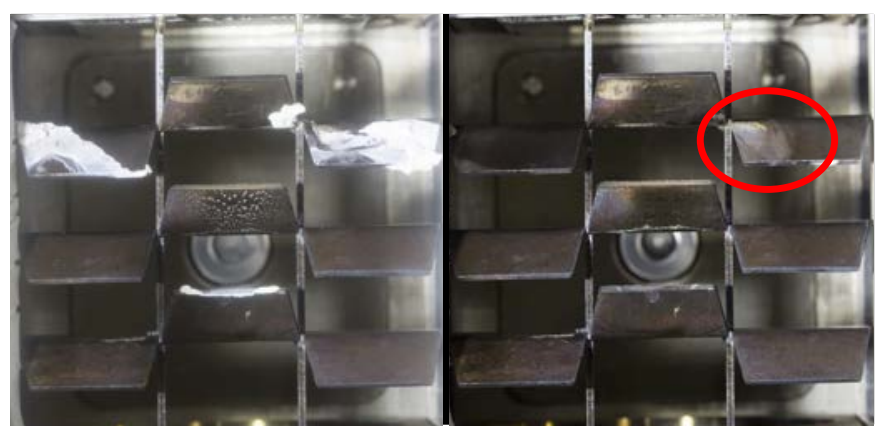

Figure 17 End view of mixer after 30 minutes with $250 \mathrm{~kg} / \mathrm{h}$ air flow at $300{ }^{\circ} \mathrm{C}$. Left $400 \mathrm{~g} / \mathrm{h}$ AUS 32. Right $400 \mathrm{~g} / \mathrm{h}$ ACCT solution

This is due to the imperfect impaction mixer/injector combination. The injector chosen has 3 distinct mass flux peaks which correspond to the three areas of deposit formation visible in Figure 17 (left). Comparably, the region which demonstrates the greatest deposit also shows the formation of a liquid film when dosing with ACCT solution (Figure 17 highlighted). This film is demonstrating rapid boiling and fully evaporates 2-5 seconds after end of dosing. 
Figure 18 shows the injector tip mid-injection. The three cores from each of the 3 nozzles can be clearly seen with larger droplet sizes.

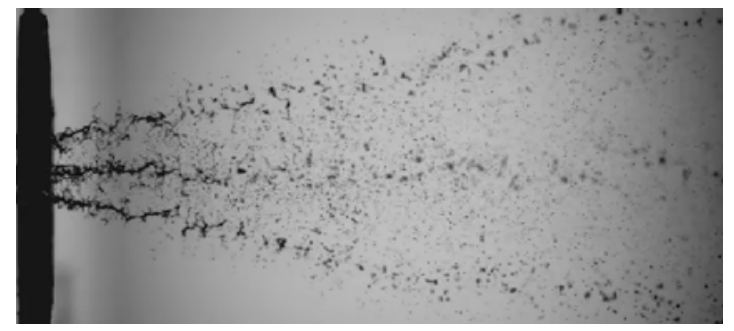

Figure 18 Injector nozzle showing 3 distinct mass streams

A series of dosing requests for $400 \mathrm{~g} / \mathrm{h}$ dose rate for 30 seconds have been used along with FTIR ammonia monitoring to assess the rate of generation from ACCT solution. A homogeneous mixture of $400 \mathrm{~g} / \mathrm{h}$ fully decomposed AUS 32 and $250 \mathrm{~kg} / \mathrm{h}$ of air flow will produce 510 ppm of ammonia. As ACCT solution has exactly the same ammonia density per unit mass this carries across.

At $400{ }^{\circ} \mathrm{C}$ an average of 25 sampling points in a $5 * 5$ grid yields an ammonia concentration of $488 \mathrm{ppm}$. Time lapse photography confirms no wetting of mixer or walls therefore the $12 \mathrm{ppm}$ deviation between the measured and theoretical limit can be attributed to a combination of measurement deviation and flow biasing as all 25 points were assumed to have a similar mass flux. This is supported by the large deviation in excess of 200 ppm between measurement points.

Figure 19 and Figure 20 depict two flow conditions at $400{ }^{\circ} \mathrm{C}$ and $100{ }^{\circ} \mathrm{C}$ respectively, each one shows the FTIR ammonia quantification from the $30 \mathrm{~s}$ injection test.

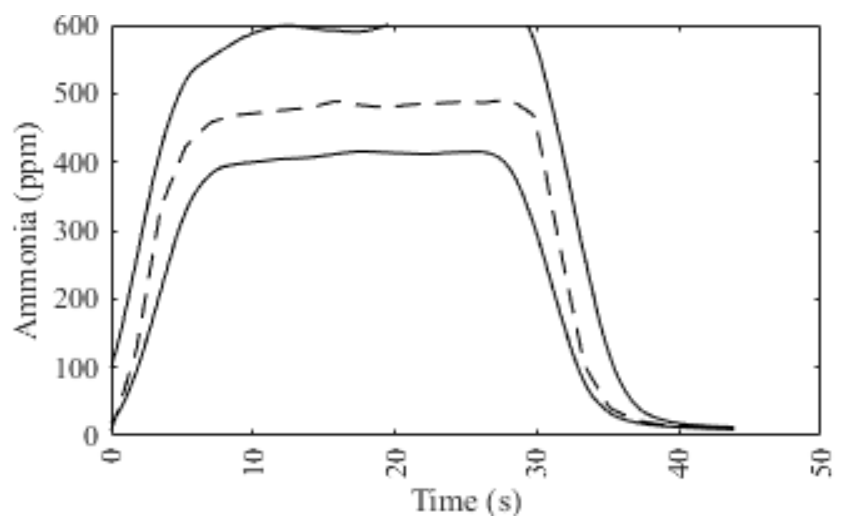

Figure 19 Ammonia concentration $800 \mathrm{~mm}$ downstream of injection in a $250 \mathrm{~kg} / \mathrm{h}$ air flow at $400{ }^{\circ} \mathrm{C}$. The dashed line depicts average ammonia concentration; maximum and minimum readings from each of the 25 sample points across the flow are shown by solid lines.

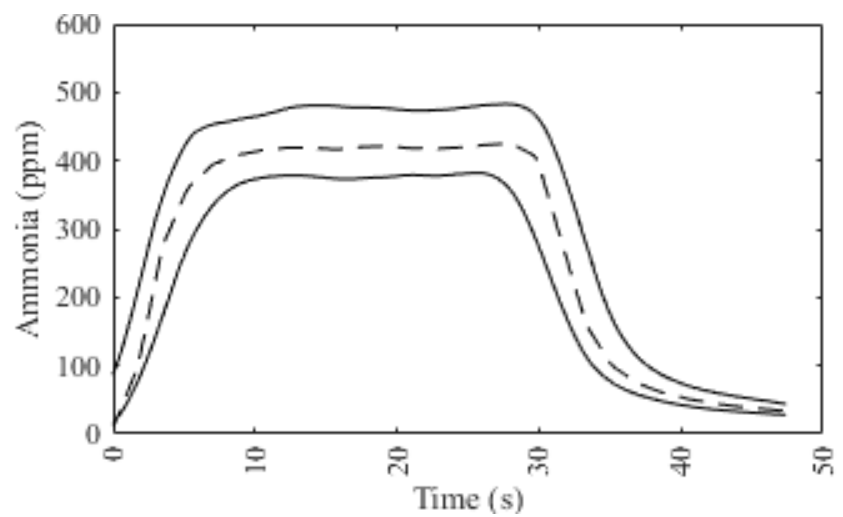

Figure 20 Ammonia concentration $800 \mathrm{~mm}$ downstream of injection in a $250 \mathrm{~kg} / \mathrm{h}$ air flow at $100{ }^{\circ} \mathrm{C}$. The dashed line depicts average ammonia concentration; maximum and minimum readings from each of the 25 sample points across the flow are shown by solid lines.

At lower exhaust temperatures of $100{ }^{\circ} \mathrm{C}$ the detected ammonia concentration is $400 \mathrm{ppm}$, it is likely that some fine droplets of undecomposed fluid are making it past the injector at this very low exhaust temperature. A portion of ammonia containing fluid is also forming a film on the mixer as a result of local cooling which delays the release of ammonia.
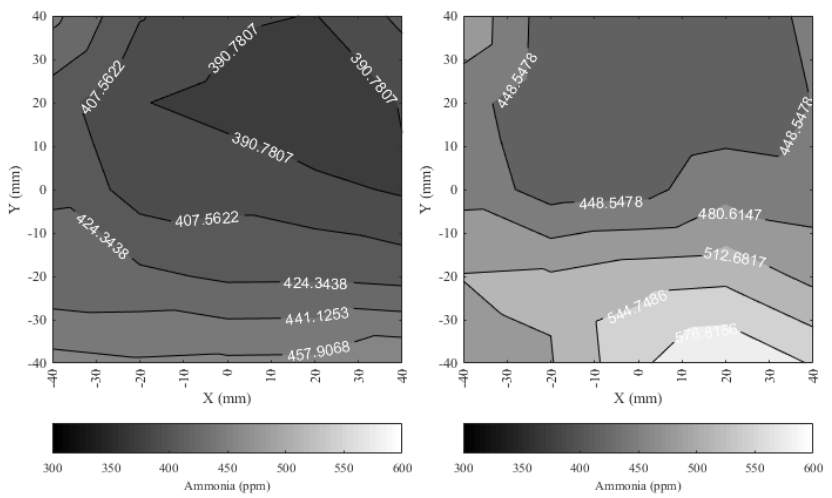

Figure 21 Ammonia concentration maps across the air flow duct. Left 100 ${ }^{\circ} \mathrm{C}$. Right $400{ }^{\circ} \mathrm{C}$.

The $90^{\circ}$ bend promotes flow biasing, as these experiments have been conducted at a constant flow rate, is exacerbated as temperature increases as a result of flow velocity increasing from $7.0 \mathrm{~m} / \mathrm{s}$ to 12.6 $\mathrm{m} / \mathrm{s}$ between 100 and $400{ }^{\circ} \mathrm{C}$. This can have an effect on measurement quality. 


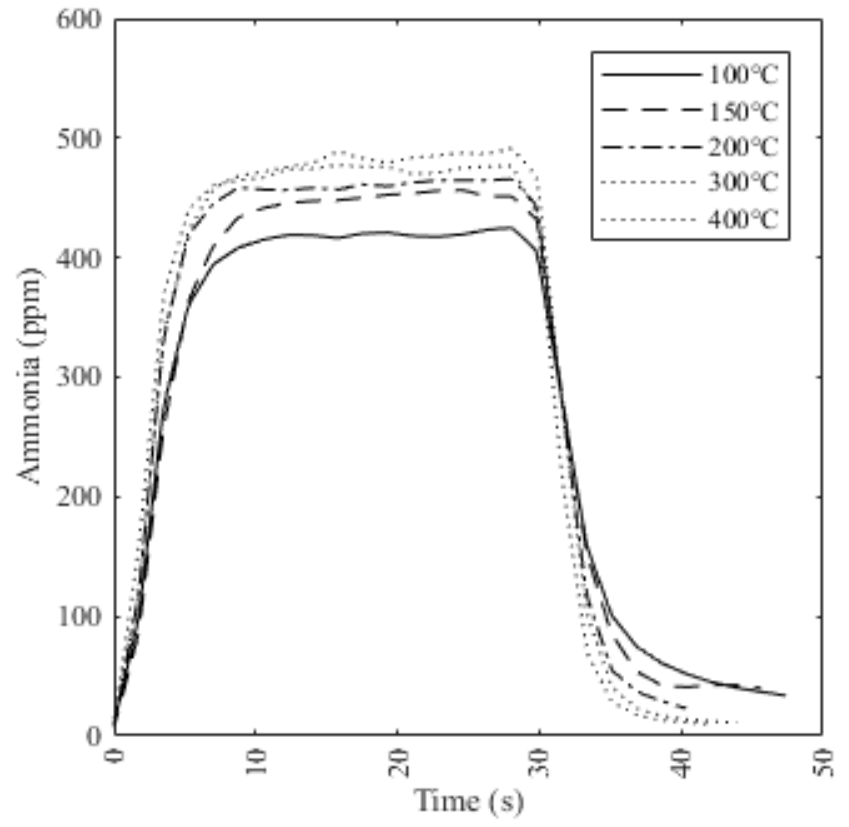

Figure 22 Ammonia concentration $800 \mathrm{~mm}$ downstream of injection in a $250 \mathrm{~kg} / \mathrm{h}$ air flow at several temperatures

Deviation in ammonia release between flow temperatures show that despite almost full decomposition even at $100{ }^{\circ} \mathrm{C}$ the process still benefits from additional flow energy. This is due to an increase in decomposition rate at higher temperature as well as a greater resistance to local surface cooling. The increased thermolysis energy of ACCT solution over AUS 32 has shown some local cooling, this is supported by a flow temperature decrease, resulting in a shallower gradient for ammonia reduction after injection has ceased. Beyond $200{ }^{\circ} \mathrm{C}$ little wall wetting or mixer wetting occurs in 30s of dosing however when left for significantly longer tests a small portion of an impaction mixer is cooled to the point of liquid film formation even at flow temperatures of $300{ }^{\circ} \mathrm{C}$. Response rate for start of injection is rapid in all test conditions, as each sample takes $1.75 \mathrm{~s}$ and it takes up to $3 \mathrm{~s}$ for a full replacement of sampled gas within the $2 \mathrm{~m}$ FTIR cell the ammonia response it beyond the limit of the detection rate.

Although close, full decomposition is not seen at any temperature, this is likely due to the non-optimised mixer design used not impacting with all droplets in the flow, as the flow velocity is high enough to leave only a fraction of a second for decomposition, shown in Table 2. This would allow a small percentage of the mass the pass the probe in its un-decomposed form. The recorded ammonia concentrations suggest that this is only a minor effect.

\section{Summary/Conclusions}

ACCT solution demonstrates ammonia production at significantly lower exhaust gas temperatures than AUS 32 alternatives. High speed shadowgraphy has shown that ACCT solution decomposes in a different manner to AUS 32. ACCT will show decomposition when placed on an $84^{\circ} \mathrm{C}$ surface and is likely to form a cellular foam as opposed to a boiling liquid when heated. The Leidenfrost point for ACCT is also lower than that of AUS 32, this appears to be largely overcome by the greater cooling capacity caused by a greater enthalpy of decomposition as well as a greater rate of decomposition. Even after a dry rebound the fluid can, in Page 11 of 13 some cases, attach to the surface and enter a rapid boiling regime. Hot flow testing has shown the viability for ACCT use at low temperatures. Decomposition is a minimum of $80 \%$ complete 800 $\mathrm{mm}$ away from the site of injection at exhaust temperatures down to $100{ }^{\circ} \mathrm{C}$ it represents a realistic method for ammonia deliver at extremely low exhaust temperatures.

\section{References}

1. EEA, “Air quality in Europe,” ISBN 978-92-9213-824-0, 2016, doi:doi:10.2800/413142.

2. Sullivan, J.L., Baker, R.E., Boyer, B.A., Hammerle, R.H., Kenney, T.E., Muniz, L., and Wallington, T.J., "CO2 emission benefit of diesel (versus Gasoline) powered vehicles,” Environ. Sci. Technol. 38(12):3217-3223, 2004, doi:10.1021/es034928d.

3. Johnson, T. and Joshi, A., "Review of Vehicle Engine Efficiency and Emissions," SAE Tech. Pap., 2017, doi:10.4271/2017-01-0907.

4. Trautwein, W.-P. (DGMK), "Research Report 616- 2 AdBlue as a Reducing Agent for the Decrease of NOx Emissions from Diesel Engines of Commercial Vehicles,” ISBN 3936418365, 2005.

5. $\quad$ Trautwein, W.-P. (DGMK), "Research Report 616-1 AdBlue as a Reducing Agent for the Decrease of NOx Emissions from Diesel Engines of Commercial Vehicles,” ISBN 3936418101, 2003.

6. Yim, S.D., Kim, S.J., Baik, J.H., Nam, I.S., Mok, Y.S., Lee, J.H., Cho, B.K., and Oh, S.H., "Decomposition of urea into NH3 for the SCR process," Ind. Eng. Chem. Res. 43(16):4856-4863, 2004, doi:10.1021/ie034052j.

7. $\quad$ Fang, H.L. and DaCosta, H.F.M., "Urea thermolysis and NOx reduction with and without SCR catalysts," Appl. Catal. B Environ. 46(1):17-34, 2003, doi:10.1016/S09263373(03)00177-2.

8. Schaber, P.M., Colson, J., Higgins, S., Thielen, D., Anspach, B., and Brauer, J., "Thermal decomposition (pyrolysis) of urea in an open reaction vessel," Thermochim. Acta 424(12):131-142, 2004, doi:10.1016/j.tca.2004.05.018.

9. $\quad$ Bernhard, A.M., Peitz, D., Elsener, M., Wokaun, A., and Kröcher, O., "Hydrolysis and thermolysis of urea and its decomposition byproducts biuret, cyanuric acid and melamine over anatase TiO2,” Appl. Catal. B Environ. 115116:129-137, 2012, doi:10.1016/j.apcatb.2011.12.013.

10. Zheng, G., Fila, A., Kotrba, A., and Floyd, R., "Investigation of Urea Deposits in Urea SCR Systems for Medium and Heavy Duty Trucks,” SAE Tech. Pap., 2010, doi:10.4271/2010-01-1941.

11. Kamasamudram, K., Currier, N., Szailer, T., and Yezerets, A., "Why Cu- and Fe-Zeolite SCR Catalysts Behave Differently At Low Temperatures," SAE Int. J. Fuels Lubr. 3(1):2010-01-1182, 2010, doi:10.4271/2010-01-1182. 

"Low-temperature selective catalytic reduction of NOx with NH3 over novel Mn-Zr mixed oxide catalysts," Ind. Eng. Chem. Res. 53(7):2647-2655, 2014, doi:10.1021/ie404224y.

13. Zhang, S., Zhang, B., Liu, B., and Sun, S., “A review of Mncontaining oxide catalysts for low temperature selective catalytic reduction of NOx with $\mathrm{NH} 3$ : reaction mechanism and catalyst deactivation," RSC Adv. 7(42):26226-26242, 2017, doi:10.1039/C7RA03387G.

14. Fisher, J. and Iii, H.W.S., "Urea to Ammonia ( U2A ${ }^{\mathrm{TM}}$ ) systems : Operation and Process Chemistry,” Europe 1-16.

15. Seneque, M., Courtois, X., Can, F., and Duprez, D., “Direct Comparison of Urea-SCR and NH3-SCR Activities Over Acidic Oxide and Exchanged Zeolite Prototype Powdered Catalysts,” Top. Catal. 59(10-12):938-944, 2016, doi:10.1007/s11244-016-0572-4.

16. Koebel, M. and Strutz, E.O., "Thermal and hydrolytic decomposition of urea for automotive selective catalytic reduction systems: Thermochemical and practical aspects," Ind. Eng. Chem. Res. 42(10):2093-2100, 2003, doi:10.1021/ie020950o.

17. Darde, V., Well, W.J.M. Van, Erling, |, Stenby, H., and Thomsen, K., "Modeling of Carbon Dioxide Absorption by Aqueous Ammonia Solutions Using the Extended UNIQUAC Model,” Jul. 2017, doi:10.1021/ie1009519.

18. Thomsen, K. and Rasmussen, P., "Modeling of vaporliquid-solid equilibrium in gas-aqueous electrolyte systems,” Chem. Eng. Sci. 54:1787-1802, 1999.

19. Thomsen, K., Rasmussen, P., and Gani, R., "CORRELATION AND PREDICTION OF THERMAL PROPERTIES AND PHASE BEHAVIOUR FOR A CLASS OF AQUEOUS ELECTROLYTE SYSTEMS,” Chem. Eng. Sci. 51(14):3675-3683, 1996.

20. ImageJ.

21. Liang, G. and Mudawar, I., "Review of drop impact on heated walls,” Int. J. Heat Mass Transf. 106:103-126, 2017, doi:10.1016/j.ijheatmasstransfer.2016.10.031.

22. Jung, J., Jeong, S., and Kim, H., "Investigation of singledroplet/wall collision heat transfer characteristics using infrared thermometry,” Int. J. Heat Mass Transf. 92:774783, 2016, doi:10.1016/j.ijheatmasstransfer.2015.09.050.

23. Wang, A.B., Lin, C.H., and Cheng, C.C., "Pattern analysis of a single droplet impinging onto a heated plate," Heat Transf. - Asian Res. 34(8):579-594, 2005, doi:10.1002/htj.20089.

24. Dan, H.J. and Lee, J.S., "Modeling and measurement of boiling point elevation during water vaporization from aqueous urea for SCR applications,” J. Mech. Sci. Technol. 30(3):1443-1448, 2016, doi:10.1007/s12206-016-0252-0.

25. Gaynor, P., Reid, B., Hargrave, G., Lockyer, T., and Wilson, Page 12 of 13
J., “An Experimental Investigation into DEF Dosing Strategies for Heavy Duty Vehicle Applications,” SAE Int. J. Engines 8(3):1196-1206, 2015, doi:10.4271/2015-01-1028.

26. Fulks, G., Fisher, G.B.., Rahmoeller, K., Wu, M.-C., D’Herde, E., and Tan, J., “A Review of Solid Materials as Alternative Ammonia Sources for Lean NOx Reduction with SCR,” SAE Tech. Pap., 2009, doi:10.4271/2009-01-0907.

27. Visser, C.W., Frommhold, P.E., Wildeman, S., Mettin, R., Lohse, D., and Sun, C., "Dynamics of high-speed microdrop impact: numerical simulations and experiments at frame-to-frame times below $100 \mathrm{ns,"} \mathrm{Soft} \mathrm{Matter}$ 11(9):1708-1722, 2015, doi:10.1039/C4SM02474E.

28. Bai, C. and Gosman, A.D., "Development of Methodology for Spray Impingement Simulation,” SAE Tech. Pap. (412):950283, 1995, doi:10.4271/950283.

29. Lockyer, T., Reid, B., Hargrave, G., Gaynor, P., and Wilson, J., "Optical Investigation on the Ability of a Cordierite Substrate Mixing Device to Combat Deposits in SCR Dosing Systems,” 2015, doi:10.4271/2015-011039.Copyright.

30. Brack, W., Heine, B., Birkhold, F., Kruse, M., and Deutschmann, O., "Formation of Urea-Based Deposits in an Exhaust System: Numerical Predictions and Experimental Observations on a Hot Gas Test Bench,” Emiss. Control Sci. Technol. 2(3):115-123, 2016, doi:10.1007/s40825-0160042-2.

31. Strots, V.O., Santhanam, S., Adelman, B.J., Griffin, G. a., and Derybowski, E.M., "Deposit Formation in Urea-SCR Systems,” SAE Int. J. Fuels Lubr. 2(2):283-289, 2009, doi:10.4271/2009-01-2780.

\section{Contact Information}

\section{Definitions/Abbreviations}

\begin{tabular}{|l|l|}
\hline DEF & Diesel Exhaust Fluid \\
\hline AUS32 & $\begin{array}{l}\text { DEF with a comprising of } \\
32.5 \% \text { wt urea and } \\
\text { demineralized water }\end{array}$ \\
\hline SCR & Selective Catalytic \\
& Reduction \\
\hline ACCT & Ammonia Creation and \\
& Conversion Technology \\
\hline $\begin{array}{l}\text { ACCT } \\
\text { solution }\end{array}$ & $\begin{array}{l}\text { A solution of ammonium } \\
\text { carbamate and water made } \\
\text { by the decomposition of } \\
\text { DEF }\end{array}$ \\
\hline
\end{tabular}




\begin{tabular}{|l|l|}
\hline AMOX & Ammonia Oxidation Catalyst \\
\hline ASC & Ammonia Slip Catalyst \\
\hline FTIR & $\begin{array}{l}\text { Fourier Transform Infrared } \\
\text { Spectroscopy }\end{array}$ \\
\hline DOF & Depth of Field \\
\hline RAM & Random Access Memory \\
\hline fps & Frames per Second \\
\hline Matlab & A computational computer \\
\hline
\end{tabular}

\begin{tabular}{|l|l|}
\hline & language \\
\hline We & Weber Number \\
\hline
\end{tabular}

Page 13 of 13 